Jurnal Algoritme

Vol. 1, No. 1, Oktober 2020, Hal. 45 - 56

\title{
Implementasi Metode Convolutional Neural Network Menggunakan Arsitektur LeNet-5 untuk Pengenalan Doodle
}

\author{
Muhammad Rafly Alwanda*1, Raden Putra Kurniawan Ramadhan ${ }^{2}$, Derry Alamsyah ${ }^{3}$ \\ ${ }^{1,2}$ STMIK Global Informatika MDP; J1. Rajawali No.14, +62(711)376400/376360 \\ 1,2Program Studi Teknik Informatika, STMIK Global Informatika MDP, Palembang \\ e-mail: *11rafly.alwanda17@mhs.mdp.ac.id, ${ }^{2}$ radenputrakurniawan@mhs.mdp.ac.id, \\ 3erry@mdp.ac.id
}

\begin{abstract}
Abstrak
Pengenalan objek sampai saat ini banyak diterapkan dalam berbagai bidang, contohnya pada pengenalan tulisan tangan (handwritten). Penelitian ini memanfaatkan kemampuan CNN menggunakan arsitektur LeNet-5 untuk pengenalan jenis doodle dengan 5 objek gambar yaitu baju, celana, kursi, kupu - kupu dan sepeda. Setiap objek doodle terdiri dari 30 gambar dengan total jumlah dataset sebanyak 150 gambar. Hasil pengujian menunjukkan bahwa skenario pertama, kedua dan keempat objek sepeda lebih dikenali dengan nilai accuracy 93\% - 98\%, recall $86 \%$ - 93\% dan precision $81 \%$ - 93\%, objek baju lebih dikenali pada skenario ketiga dengan nilai accuracy $94 \%$, recall $86 \%$, dan precision $83 \%$.
\end{abstract}

Kata kunci-Convolutional Neural Network, Doodle, LeNet-5, Handwritten

\begin{abstract}
Recognition of objects to date has been widely applied in various fields, for example in handwritten recognition. This research utilizes the ability of CNN to use LeNet-5 architecture for the introduction of doodle types with 5 object images, namely clothes, pants, chairs, butterflies and bicycles. Each doodle object consists of 30 images with a total dataset of 150 images. The test results show that the first, second and fourth scenarios of bicycle objects are more recognized with an accuracy value of $93 \%$ - 98\%, recall $86 \%$ - 93\% and precision $81 \%$ $93 \%$, clothes objects are more recognized in the third scenario with an accuracy value of $94 \%$, $86 \%$ recall, and $83 \%$ precision.
\end{abstract}

Keywords - Convolutional Neural Network, Doodle, LeNet-5, Handwritten

\section{PENDAHULUAN}

$\mathrm{P}$ engenalan objek sampai saat ini telah banyak diterapkan dalam berbagai bidang, salah satunya adalah pengenalan tulisan tangan (handwritten). Ada banyak jenis metode yang digunakan untuk melakukan pengenalan citra, yaitu Kecerdasan Buatan (Artificial Intelligence), Pembelajaran Mesin (Machine Learning) dan Pembelajaran Dalam (Deep Learning). Kecerdasan Buatan (Artificial Intelligence) adalah jenis metode yang memiliki cara kerja meniru kecerdasan seperti makhluk hidup untuk menyelesaikan persoalan, sedangkan Pembelajaran Mesin (Machine Learning) merupakan pendekatan dari Kecerdasan Buatan yang dapat menirukan atau menggantikan perilaku manusia untuk menyelesaikan masalah dan Pembelajaran Dalam (Deep Learning) adalah teknik dalam Pembelajaran Mesin yang menirukan syaraf manusia yang merupakan bagian fundamental dari otak [1]. Salah satu contoh metode klasifikasi yang digunakan dalam pembelajaran mesin yaitu Multi Layer Perceptron 
(MLP). Penelitian sebelumnya banyak yang menggunakan metode tersebut untuk melakukan pengenalan objek tulisan tangan, contohnya pada pengenalan karakter tulisan tangan alpabet dalam bahasa Bangladesh menggunakan metode Multi Layer Perceptron (MLP) mendapatkan tingkat akurasi sebesar 75,08\% [2], lalu penelitian pengenalan tulisan tangan berupa kata kunci menggunakan bahasa Arab, Inggris dan Farsi dengan metode Multi Layer Perceptron (MLP) menghasilkan tingkat akurasi sebesar $83 \%$ pada tulisan Arab, $77 \%$ pada tulisan Inggris dan $69 \%$ pada tulisan Farsi [3].

Deep Learning adalah sebuah model jaringan syaraf tiruan yang sekarang ini mulai banyak digunakan dan dikembangkan pada kasus pengenalan citra dikarenakan perkembangan teknologi Graphic Processing Unit (GPU). Deep Learning dinilai dapat memiliki tingkat akurasi yang tinggi. Salah satu contoh Deep Learning yang digunakan untuk pengenalan citra adalah Convolutional Neural Network (CNN). Convolutional Neural Network (CNN) adalah pengembangan dari metode Multi Layer Perceptron (MLP). Metode Convolutional Neural Network (CNN) lebih baik daripada metode Multi Layer Perceptron (MLP) dikarenakan metode Convolutional Neural Network (CNN) memiliki kedalaman jaringan yang tinggi dan sering diaplikasikan pada data pengenalan citra sehingga mampu menghasilkan tingkat akurasi tinggi dan hasil yang baik, sedangkan metode Multi Layer Perceptron (MLP) dinilai kurang baik daripada metode Convolutional Neural Network (CNN) dikarenakan metode Multi Layer Perceptron (MLP) tidak menyimpan informasi spasial dari data pengenalan citra dan menganggap bahwa setiap piksel adalah fitur yang independen sehingga menghasilkan hasil yang kurang baik [4].

Arsitektur pada Convolutional Neural Network (CNN) memiliki kemampuan untuk mengekstraksi fitur secara otomatis. Banyak macam arsitektur Convolutional Neural Network (CNN) yang populer untuk digunakan, contohnya LeNet-5 (1998), AlexNet (2012), ZFNet (2013), VGGNet (2014), GoogLeNet (2014), ResNet (2015), FractalNet (2016) dan arsitektur yang lainnya [5]. LeNet-5 adalah arsitektur CNN yang terdiri dari suatu jaringan berlapis banyak sehingga LeNet-5 memiliki jumlah parameter bebas atau jumlah lapisan yang lebih banyak daripada arsitektur lainnya, sedangkan AlexNet, GoogleNet, VGGNet dan ResNet membutuhkan terlalu banyak waktu untuk komputasi dan konfigurasi perangkat keras untuk melatih jaringan syaraf tiruan. LeNet-5 adalah metode CNN pertama yang telah berhasil diterapkan untuk pengenalan digital [6]. LeNet-5 lebih banyak digunakan pada klasifikasi tulisan tangan (handwritten) sedangkan AlexNet, ZFNet, VGGNet, GoogleNet dan ResNet sering digunakan untuk klasifikasi gambar, segmentasi, deteksi objek dan penggabungan gambar [7]. Penggunaan arsitektur LeNet-5 yang dikombinasikan dengan metode CNN mampu mencapai tingkat akurasi hingga 98\% dengan hanya menggunakan fitur biner yang sederhana [8], pada penelitian klasifikasi tulisan tangan menggunakan arsitektur LeNet-5 sebagai ekstraksi untuk klasifikasi tulisan tangan mendapatkan tingkat akurasi sebesar 98\% [9] dan penelitian yang membandingkan antara arsitektur LeNet-5 dan VGG Net dalam rekognisi angka tahun pada prasasti peninggalan kerajaan Majapahit dapat disimpulkan bahwa Performansi LeNet-5 ini lebih baik daripada model VGG Net dengan jarak perbandingan sebesar $11,39 \%$ pada 10 epoch dalam waktu proses 40223 detik [10].

Penelitian dilakukan untuk mengenali jenis doodle yang digambar pada canvas berbasis web berdasarkan data dan informasi yang diperoleh dari data citra. Konsep doodle diaplikasikan pada penelitian ini dikarenakan doodle adalah gambaran atau suatu goresan yang dapat dibuat dengan media apapun seperti kertas, spidol, pensil, kuas dan lainnya [11], doodle juga dapat dibuat secara langsung tanpa menggunakan sketsa sehingga karya seni ini lebih familiar dengan dunia masyarakat luas, selain itu tujuan lain dari pemilihan doodle sebagai objek penelitian ini adalah untuk menarik perhatian mahasiswa agar dapat mengasah tingkat kreativitas dan dapat berfikir lebih luas karena untuk melakukan penggambaran doodle hanya membutuhkan imajinasi yang ada didalam pikiran secara spontan pada dasarnya dapat menghasilkan bentuk bentuk yang imajinatif dan beragam serta dapat digambar dengan kombinasi banyak media.

Alwanda, et., al ( Implementasi Metode Convolutional Neural Network Menggunakan Arsitektur LeNet-5 untuk Pengenalan Doodle) 


\section{METODE PENELITIAN}

\subsection{Identifikasi Masalah}

Penelitian dimulai dengan mencari topik - topik mengenai perkembangan penelitian tentang pengenalan doodle.

\section{1.1Doodle}

Doodle adalah gambaran atau goresan yang dapat dibuat dengan menggunakan media seperti kertas, spidol pensil, kuas, pulpen dan lainnya dengan penggambaran pola yang ramai. Doodle juga biasa disebut gambaran ilustrasi yang berupa gambaran tangan secara manual atau sketching. Berikut ini adalah contoh dari penggambaran doodle.

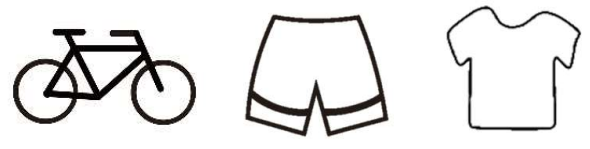

Gambar 1. Contoh Gambaran Doodle

\section{2 Studi Literatur}

Tahapan ini merupakan pencarian beberapa jurnal dan buku yang terkait mengenai pengenalan doodle atau handwriting dengan menggunakan berbagai macam metode yang digunakan, jurnal yang terkait dengan metode Convolutional Neural Network (CNN) dan berbagai macam arsitektur CNN yang digunakan seperti LeNet-5

\section{2.1 Convolutional Neural Network}

Convolutional Neural Network adalah pengembangan dari Multi Layer Perceptron (MLP) yang digunakan untuk mengolah data dua dimensi. Convolutional Neural Network (CNN) termasuk dalam Deep Neural Network yang banyak digunakan pada citra dengan jaringan yang tinggi dan banyak diaplikasikan pada data penelitian citra. Convolutional Neural Network (CNN) terdiri dari lapis masukan (input layer), lapis keluaran (output layer) dan sejumlah lapisan tersembunyi (hidden Layers). Pada lapisan tersembunyi (hidden layers) berisi convolutional layers, pooling layers dan fully connected layers [12]. Berikut ini adalah gambar lapisan pada metode Convolutional Neural Network.

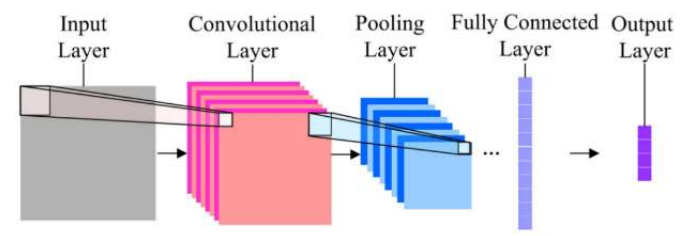

Gambar 2. Model Lapisan Comvolutional Neural Network

Convolutional layer adalah lapisan yang digunakan untuk melakukan operasi konvolusi pada output layer sebelumnya. Layer ini termasuk blok utama pada Convolutional Neural Network (CNN) yang didalamnya terdiri dari filter - filter yang di pelajari secara acak untuk melakukan operasi konvolusi yang bertujuan sebagai ekstraksi fitur untuk mempelajari representasi fitur dari input layer. Tujuan dilakukannya operasi konvolusi pada data citra untuk mengekstraksi fitur dari input citra. Konvolusi tersebut akan menghasilkan transformasi linear dari data yang di input sesuai informasi spasial yang tersedia pada data. Bobot pada layer

Alwanda, et., al (Implementasi Metode Convolutional Neural Network Menggunakan Arsitektur LeNet-5 untuk Pengenalan Doodle) 
tersebut akan menspesifikasikan kernel konvolusi yang digunakan sehingga kernel konvolusi dapat dilatih berdasarkan input pada Convolutional Neural Network (CNN) [4].

Pooling layer adalah lapisan yang berfungsi untuk mengurangi ukuran spasial dari fitur konvolusi sehingga dapat mengurangi sumber daya komputasi yang dibutuhkan untuk memproses data melalui pengurangan dimensi dari feature map (downsampling) sehingga mempercepat komputasi karena paramter yang diperbarui semakin sedikit. Selain itu, berguna untuk mengekstraksi fitur dominan sehingga proses pelatihan model lebih efektif. Ada dua jenis pooling layer, yaitu max pooling dan average pooling [13]. Max pooling mengembalikan nilai maksimum dari bagian gambar yang dicakup oleh kernel sedangkan average pooling mengembalikan nilai rata - rata dari bagian gambar yang dicakup oleh kernel.

Fully connected layer adalah lapisan yang digunakan untuk melakukan transformasi pada dimensi data agar data dapat diklasifikasikan secara linear. Untuk mendapatkan hasil keluaran dari layer ini tidak dibutuhkan operasi konvolusi, tetapi menggunakan komputasi perkalian matriks yang diikuti dengan bias offset. Dengan penggunaan operasi tersebut, setiap neuron memiliki koneksi penuh ke semua aktivasi dalam lapisan sebelumnya, sehingga layer ini disebut sebagai fully conected layer [12].

Fungsi aktivasi atau disebut juga neuron merupakan fungsi non-linear yang memungkinkan sebuah jaringan syaraf tiruan untuk menyelesaikan permasalahan non-trivial. Setiap fungsi aktivasi mengambil sebuah nilai dan melakukan operasi matematika. Fungsi aktivasi pada arsitektur Convolutional Neural Network (CNN) terletak pada perhitungan akhir keluaran feature map atau sesudah proses perhitungan konvolusi atau pooling untuk menghasilkan suatu pola fitur [14].

\section{2.2 LeNet-5}

LeNet-5 adalah suatu jaringan yang memiliki lapisan banyak berbasis Convolutional Neural Network (CNN) pertama kali yang dikenalkan oleh Yann LeCun. LeNet 5 terbentuk dari pengembangan - pengembangan versi LeNet sebelumnya, sehingga LeNet 5 ini mempunyai jumlah lapisan yang lebih banyak daripada versi LeNet sebelumnya. Seiring perkembangan dan majunya kecepatan teknologi dari komputer, maka lapisan LeNet 5 ini mengalami pertambahan sehingga komputer dapat lebih cepat melakukan komputasi atau perhitungan matematis secara cepat [8]. Berikut ini adalah gambar arsitektur LeNet-5.

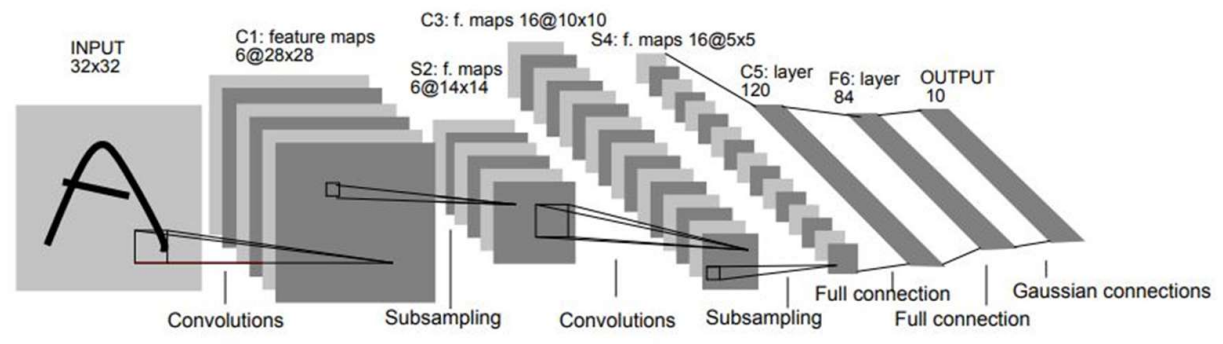

Gambar 3. Arsitektur LeNet-5 pada Comvolutional Neural Network

Input untuk LeNet-5 adalah gambar skala abu-abu yang berukuran $32 \times 32 \times 1$ melalui lapisan convolutional dengan 6 feature maps dengan ukuran filter $5 \times 5$ dan satu stride. 6 feature maps ini adalah channel dari gambar yang sudah dilakukan operasi konvolusi dengan setiap ukuran 28x28x6. Stride digunakan untuk mengontrol seberapa besar pergeseran dari suatu filter pada layer saat melewati serangkaian data. Pada lapisan ini digunakan fungsi aktivasi tanh yang terdapat pada kernel size. Untuk mendapatkan dimensi yang baru, dapat digunakan persamaan (1) dan (2).

Alwanda, et., al ( Implementasi Metode Convolutional Neural Network Menggunakan Arsitektur LeNet-5 untuk Pengenalan Doodle) 


$$
\begin{aligned}
& \text { output width }=\left(\frac{\mathrm{w}-\mathrm{Fw}+2}{\mathrm{Sw}}\right)+1 \\
& \text { output height }=\left(\frac{\mathrm{h}-\mathrm{Fh}+2 \mathrm{p}}{\mathrm{sh}}\right)+1
\end{aligned}
$$

Kemudian Lapisan kedua (S2) merupakan lapisan pooling layer dengan ukuran filter 2×2, 6 feature maps dan dua stride. Pada lapisan ini masih sama dengan lapisan sebelumnya menggunakan fungsi aktivasi tanh. Dengan menggunakan rumus (1) dan (2) maka didapatkan dimensi gambar yang dihasilkan menjadi 14x14x6.

Selanjutnya ada lapisan convolutional kedua dengan 16 feature maps yang memiliki ukuran filter $5 \times 5$ dengan fungsi aktivasi tanh dan satu stride, dengan menggunakan rumus (1) dan (2) maka didapakan dimensi gambar berukuran 10x10x16.

Lapisan keempat (S4) merupakan pooling layer dengan jenis average pooling layer atau max pooling layer yang memiliki filter berukuran $2 \times 2$ dengan aktivasi tanh dan dua stride. Lapisan ini hampir sama dengan lapisan kedua (S2), hanya saja pada lapisan ini memiliki 16 feature maps. Pada lapisan ini terdapat 400 nodes yang akan dihubungkan dengan 5x5x16.

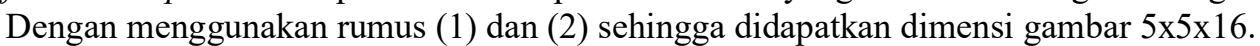

Lapisan kelima (C5) merupakan fully connected layer dengan 120 feature maps pada masing - masing ukuran 1X1 dengan fungsi aktivasi tanh. Masing - masing dari 120 nodes di lapisan kelima terhubung ke semua 400 nodes yang ada di lapisan keempat (S4). 120 nodes ini telah ditetapkan dari arsitektur LeNet-5. Untuk mendapatkan parameter latih dapat digunakan persamaan berikut ini:

$$
\text { trainable params }=(\text { input maps }+ \text { bias }) \times \text { feature maps }
$$
ini:

Untuk mendapatkan jumlah nodes yang terhubung, dapat digunakan persamaan berikut

$$
\text { connections }=\text { trainable params } x \text { feature maps size }
$$

Pada kasus ini, bias selalu bernilai 1. Setelah dihitung menggunakan rumus (3) maka didapatkan parameter latih sebanyak 48120 dan didapatkan jumlah nodes yang terhubung yang dihitung menggunakan rumus (4) sebanyak 48120.

Untuk lapisan keenam (F6) merupakan fully connected layer dengan nodes yang berjumlah sebanyak 84 nodes. Untuk mendapatkan parameter latih dan jumlah nodes yang terhubung dapat digunakan rumus (3) dan (4), maka didapatkan parameter latih sebanyak 10164 nodes.

Pada lapisan terakhir atau output layer merupakan fully connected yang menggunakan fungsi aktivasi softmax dengan size 5 berdasarkan dengan hasil output gambar yang diklasifikasikan.

\section{2.3 Tensorflow}

Tensorflow adalah sebuah library pada machine learning atau sering disebut dengan deep learning, Tensorflow mampu digunakan untuk melakukan pengenalan suara, mengenali wajah dalam sebuah foto dan pengenalan objek pada gambar yang dapat digunakan pada sebuah aplikasi perangkat lunak yang berbasis open source [15].

\section{2.4 Keras}

Keras merupakan perangkat lunak jaringan yang berbasis open source ditulis dengan menggunakan bahasa Python. Keras juga dapat dijalankan menggunakan MXNet, Tensorflow, Deeplearning4j, theano atau CNTK yang khusus dirancang guna mempercepat eksperimen yang berhubungan dengan deep learning. Keras dikembangkan untuk eksperimen proyek ONEIROS

Alwanda, et., al (Implementasi Metode Convolutional Neural Network Menggunakan Arsitektur LeNet-5 untuk Pengenalan Doodle) 
(Open-ended Neuro-Electronic Intelligent Robot Operating System) yang dikelola dan ditulis oleh Francois Chollet, seorang insinyur yang bekerja di Google [16].

\section{3 Pengumpulan Data}

Pengumpulan data menggunakan dataset yang berjumlah 150 gambar yang didapatkan dari 30 orang dengan rentang usia 17 sampai 24 tahun, masing - masing orang menggambar 5 jenis doodle yaitu sepeda, celana, baju, kursi dan kupu - kupu. Setiap objek dataset memiliki resolusi sekitar 32x32 piksel dan berformat *.JPG. Berikut adalah jumlah data yang terdapat pada setiap jenis doodle dapat dilihat pada tabel 1 .

Tabel 1. Data Setiap Jenis Doodle

\begin{tabular}{|l|c|}
\hline $\begin{array}{c}\text { Jenis - Jenis } \\
\text { Doodle }\end{array}$ & $\begin{array}{c}\text { Jumlah Masing- } \\
\text { Masing Dataset }\end{array}$ \\
\hline Sepeda & 30 Gambar \\
\hline Celana & 30 Gambar \\
\hline Baju & $30 \mathrm{Gambar}$ \\
\hline Kursi & $30 \mathrm{Gambar}$ \\
\hline Kupu - Kupu & $30 \mathrm{Gambar}$ \\
\hline \multicolumn{1}{|c|}{ Total } & $150 \mathrm{Gambar}$ \\
\hline
\end{tabular}

\section{4 Perancangan Sistem} berikut.

Pada tahap ini dilakukan perancangan sistem, proses ini dapat dilihat pada gambar

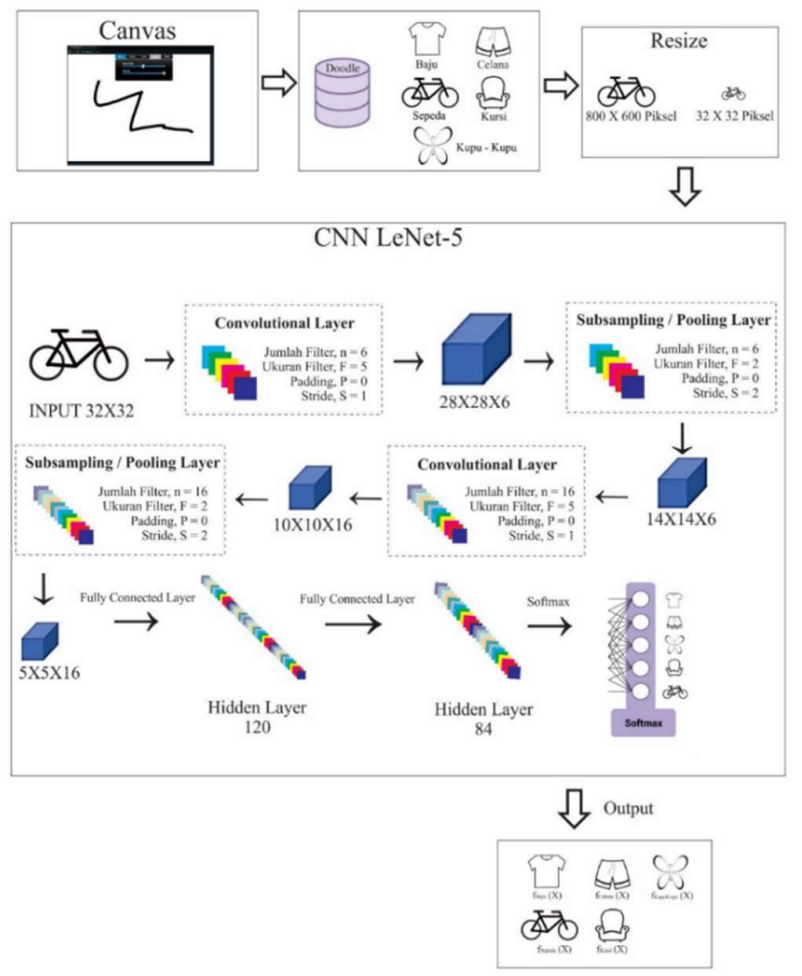

Gambar 4. Rancangan Metodologi

Alwanda, et., al ( Implementasi Metode Convolutional Neural Network Menggunakan Arsitektur LeNet-5 untuk Pengenalan Doodle) 
Perancangan sistem dilakukan dengan membuat perancangan aplikasi canvas berbasis web yang digunakan untuk melakukan penggambaran doodle, selain itu canvas juga dibutuhkan sebagai media untuk melakukan pengambilan dataset. Dataset yang telah didapatkan akan di resize sesuai input citra yang diterima oleh arsitektur LeNet-5 yaitu $32 \times 32$ piksel. Setelah dataset di resize, kemudian dilakukan pengolahan menggunakan metode Convolutional Neural Network (CNN) dengan arsitektur LeNet-5. Diawali dengan input layer dengan ukuran 32x32 piksel, lalu dilakukan operasi konvolusi pada convolutional layer dengan filter $5 \times 5$ sehingga dimensi gambar berubah menjadi 28x28x6 piksel, setelah itu dilakukan lagi operasi konvolusi pada convolutional layer dengan jumlah 16 feature maps sehingga dimensi gambar berkurang menjadi 10x10x16 piksel, lalu ke tahap pooling layer dengan jumlah 16 feature maps sehingga ukuran piksel menjadi $5 \times 5 \times 16$, lalu dilakukan transformasi dimensi menjadi bentuk linear pada fully connected layer dengan jumlah 120 feature maps terhubung ke semua 400 node, dari tahap input layer sampai tahap fully connected layer menggunakan fungsi aktivasi tanh untuk mendapatkan nilai output, setelah itu dilakukan perkalian matriks diikuti dengan 84 bias offset dan tahap terakhir pada softmax. Pada bagian softmax ini keluaran output akan menghasilkan bentuk neuron yang saling terhubung kepada objek yang telah ditentukan seperti baju, celana, kursi, kupu-kupu dan sepeda, hasil akhir output berupa persentase tergantung peluang tingkat kemiripan. Setelah proses selesai, maka data hasil telah didapatkan dan dapat digunakan pada saat pengujian untuk mengenali objek doodle.

\section{HASIL DAN PEMBAHASAN}

\section{1 Implementasi}

Tahap ini mengimplementasikan proses pada penelitian untuk memperoleh hasil yang dibutuhkan pada penelitiain ini.

\section{1.1 Implementasi Metode Convolutional Neural Network (CNN)}

Pada tahap ini dilakukan resize terhadap citra doodle sebanyak 150 gambar yang digambar pada canvas untuk dilatih, citra awal berukuran 800x600 piksel lalu di resize menjadi $32 \times 32$ piksel. Kemudian setiap jenis citra doodle diberi label sesuai dengan klasifikasinya lalu dilakukan proses pelatihan (training) menggunakan metode Convolutional Neural Network (CNN) dengan arsitektur LeNet-5. Pada penelitian ini digunakan dua cara pelatihan yang berbeda, yaitu menggunakan average pooling pada pooling layer untuk data latih pertama dan menggunakan max pooling pada pooling layer untuk data latih kedua, sehingga didapatkan 2 model yang berbeda, yaitu model data latih menggunakan average pooling dan model data latih menggunakan max pooling. Untuk tahap pelatihan menggunakan average pooling dapat dilihat pada Gambar 5.

\begin{tabular}{|c|c|c|}
\hline $\begin{array}{l}\text { Layer (type) } \\
\text { (tope }\end{array}$ & Output Shape & Param \# \\
\hline conv2d (Conv2D) & (None, $28,28,6$ ) & 156 \\
\hline average_pooling2d (AveragePo & (None, 14, 14, 6) & 0 \\
\hline conv2d_1 (Conv2D) & (None, $10,10,16$ ) & 2416 \\
\hline average_pooling2d_1 (Average & (None, $5,5,16$ ) & 0 \\
\hline flatten (Flatten) & (None, 400) & 0 \\
\hline dense (Dense) & (None, 120) & 48120 \\
\hline dense_1 (Dense) & (None, 84) & 10164 \\
\hline $\begin{array}{l}\text { dense_2 (Dense) } \\
======================== \\
\text { Total params: } 61,281 \\
\text { Trainable params: } 61,281 \\
\text { Non-trainable params: } \theta\end{array}$ & $\begin{array}{l}\text { (None, 5) } \\
=========\end{array}$ & $\begin{aligned} & 425 \\
== & =======\end{aligned}$ \\
\hline
\end{tabular}

Gambar 5. Ringkasan dari Arsitektur LeNet-5 menggunakan Average Pooling

Alwanda, et., al (Implementasi Metode Convolutional Neural Network Menggunakan Arsitektur LeNet-5 untuk Pengenalan Doodle) 
Pada Convolutional Layer, citra yang di masukkan berukuran 32x32 piksel dilakukan operasi konvolusi dengan filter size 5x5 dan feature maps yang berjumlah 6 channel sehingga dimensi gambar berubah menjadi 28x28x6 piksel, lalu pada average pooling dilakukan pengurangan dimensi dari feature maps (downsampling) sehingga gambar berubah menjadi $14 \times 14 \times 6$ piksel, setelah itu dilakukan lagi operasi konvolusi pada convolutional layer dengan jumlah 16 feature maps sehingga dimensi gambar berkurang menjadi 10x10x16 piksel, lalu ke tahap pooling layer dengan jumlah 16 feature maps sehingga ukuran piksel menjadi $5 \times 5 \times 16$. Pada tahap ini feature maps yang dihasilkan masih berbentuk multi dimensional array, sehingga dilakukan flatten atau reshape feature maps menjadi bentuk 1 dimensi array agar dapat digunakan sebagai input dari fully connected layer dengan jumlah 120 feature maps yang terhubung ke semua 400 node. Dimulai dari tahap convolutional layer sampai tahap fully connected layer / dense layer menggunakan fungsi aktivasi tanh untuk mendapatkan nilai output, setelah itu dilakukan perkalian matriks diikuti dengan sebanyak 84 bias offset dan tahap terakhir pada softmax keluaran output sebanyak 5 node yang akan menghasilkan bentuk neuron yang saling terhubung kepada objek doodle yang telah diberikan label, seperti baju, celana, kupu - kupu, kursi, dan sepeda. Hasil data yang telah dilatih akan disimpan kedalam model yang dapat digunakan untuk pengujian. Selanjutnya melakukan pelatihan menggunakan max pooling pada pooling layer, untuk tahap - tahap pelatihannya dapat dilihat pada Gambar 6.

\begin{tabular}{|c|c|c|}
\hline Layer (type) & Output Shape & Param \# \\
\hline conv2d_10 (Conv2D) & (None, $28,28,6$ ) & 156 \\
\hline max_pooling2d_10 (MaxPooling & (None, $14,14,6)$ & $\theta$ \\
\hline conv2d_11 (Conv2D) & (None, $10,10,16)$ & 2416 \\
\hline max_pooling2d_11 (MaxPooling & (None, $5,5,16$ ) & $\theta$ \\
\hline flatten_5 (Flatten) & (None, 400) & 0 \\
\hline dense_15 (Dense) & (None, 120) & 48120 \\
\hline dense_16 (Dense) & (None, 84) & 10164 \\
\hline dense_17 (Dense) & (None, 5) & 425 \\
\hline $\begin{array}{l}=====================- \\
\text { Total params: } 61,281 \\
\text { Trainable params: } 61,281 \\
\text { Non-trainable params: } \theta\end{array}$ & & \\
\hline
\end{tabular}

Gambar 6. Ringkasan dari Arsitektur LeNet-5 menggunakan Max Pooling

\section{1.2 Implementasi Antarmuka Aplikasi Canvas}

Tampilan akhir antarmuka aplikasi canvas yang dibangun adalah sebagai berikut :

\section{1.2.1 Halaman Depan Canvas}

Gambar 7 adalah tampilan halaman pertama aplikasi yang muncul ketika aplikasi dijalankan. Halaman ini digunakan untuk menggambar objek doodle yang akan dilakukan pengujian. Pada halaman ini terdapat tombol pencil yang dapat digunakan untuk menambahkan goresan pada canvas, tombol erase untuk menghapus goresan pada canvas, tombol save untuk menyimpan goresan pada canvas, tombol testing untuk melakukan pengujian pada objek doodle yang telah digambar dan tombol reset digunakan untuk mengatur ulang canvas agar kembali pada posisi awal.

\footnotetext{
Alwanda, et., al ( Implementasi Metode Convolutional Neural Network Menggunakan
} Arsitektur LeNet-5 untuk Pengenalan Doodle) 
Vol. 1, No. 1, Oktober 2020, Hal. 45 - 56

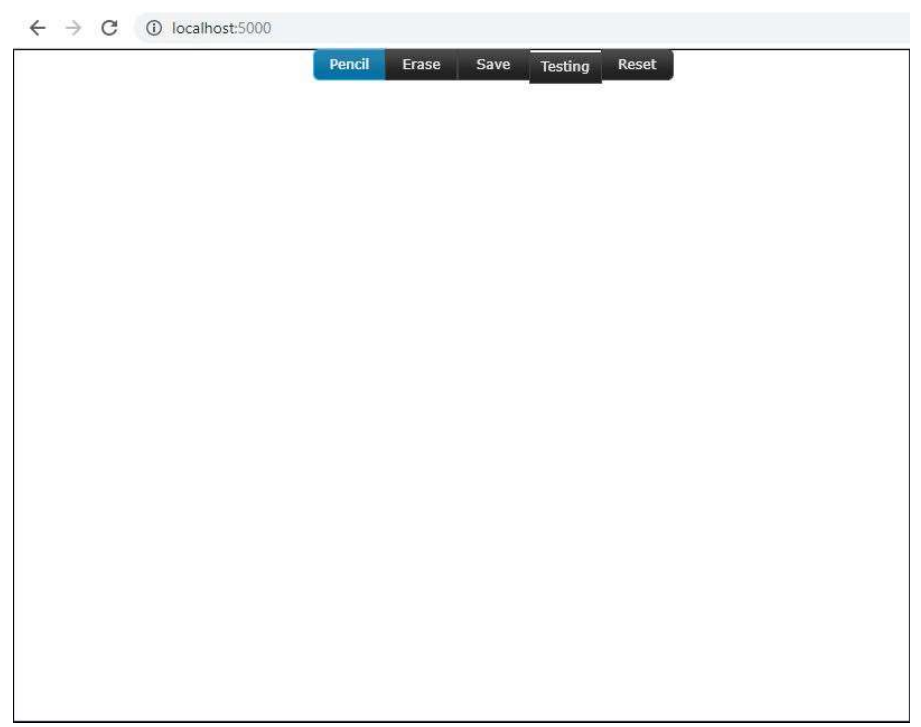

Gambar 7. Tampilan Halaman Depan Canvas

\section{1.2.2 Halaman Testing Canvas}

Gambar 8 adalah tampilan halaman pengujian, halaman ini tampil jika pengguna menekan tombol testing pada gambar 4.4. Pada halaman ini terdapat tampilan hasil dari pengujian menggunakan average pooling dan hasil dari pengujian menggunakan max pooling beserta label dari gambar yang di tebak. Selain itu, terdapat tombol start yang digunakan untuk kembali kehalaman depan aplikasi canvas.

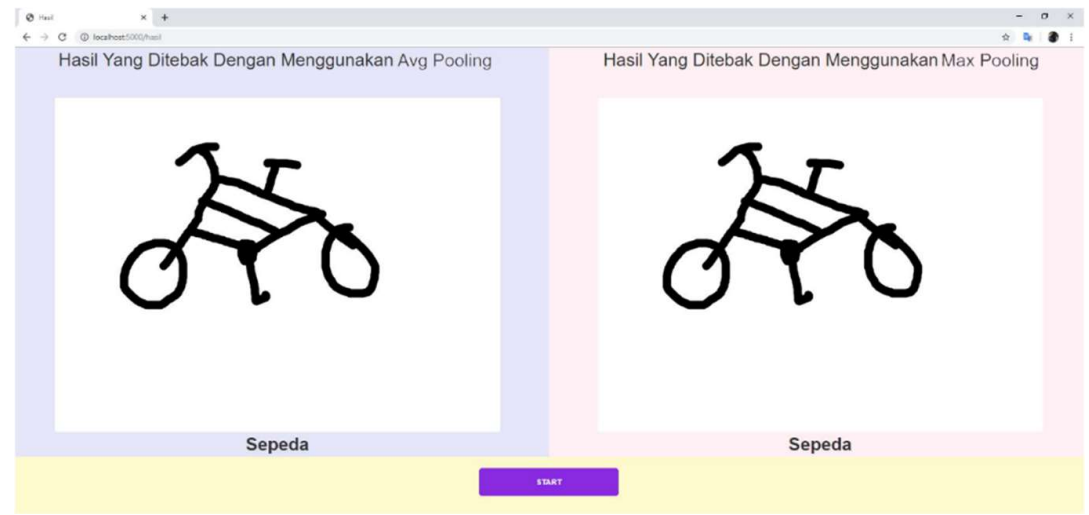

Gambar 8. Tampilan Halaman Testing Canvas

\section{2 Evaluasi}

Pada tahap ini terdapat empat skenario pengujian, yaitu :

1. Penggambaran objek doodle secara baik dengan menggunakan max pooling pada pooling layer.

2. Penggambaran objek doodle secara garis putus - putus dengan menggunakan max pooling pada pooling layer.

3. Penggambaran objek doodle secara baik menggunakan average pooling pada pooling layer.

Alwanda, et., al (Implementasi Metode Convolutional Neural Network Menggunakan Arsitektur LeNet-5 untuk Pengenalan Doodle) 
4. Penggambaran objek doodle secara garis putus - putus menggunakan average pooling pada pooling layer.

Keempat skenario ini digunakan pada setiap pengujian pengenalan jenis doodle. Sebanyak 300 gambar citra digunakan untuk pengujian yang terdiri dari 150 gambar baik dan 150 gambar dengan objek garis putus - putus. Gambar yang digunakan untuk pengujian didapatkan dari 30 orang dengan masing - masing orang menggambar 5 jenis doodle yaitu baju, celana, kupu - kupu, kursi, dan sepeda secara baik dan secara garis putus - putus. Hasil dari pengujian akan dihitung untuk mendapatkan tingkat keberhasilan dengan menggunakan confusion matrix agar didapatkan nilai precision, recall, dan accuracy. Berikut ini adalah tabel hasil pengujian per-kelas.

Tabel 2. Hasil Pengujian Per-Kelas

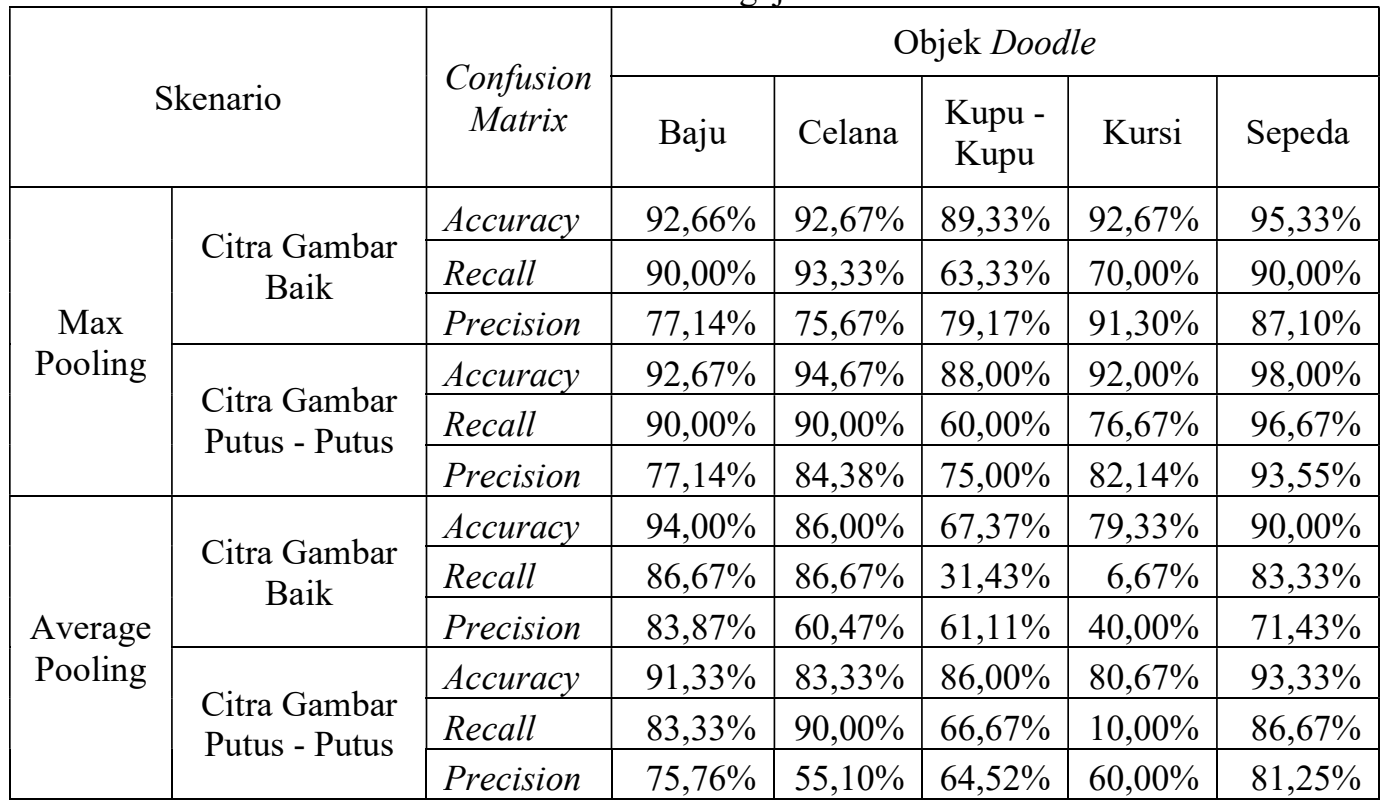

Berikut ini adalah tabel yang menunjukkan hasil pengujian keseluruhan berdasarkan skenario.

Tabel 3. Hasil Pengujian Skenario ke-1

\begin{tabular}{|c|c|c|c|c|c|c|}
\hline Kategori & Baju & Celana & Kupu - Kupu & Kursi & Sepeda & Total \\
\hline Total Data Uji Benar & 27 & 28 & 19 & 21 & 27 & 122 \\
\hline $\begin{array}{c}\text { Total Seluruh Data yang } \\
\text { Diuji }\end{array}$ & 30 & 30 & 30 & 30 & 30 & 150 \\
\hline & \multicolumn{7}{|c|}{$\begin{array}{c}\text { Data Uji Benar } \\
\text { Accuracy Keseluruhan Uji }\end{array} 100 \%=\frac{122}{150} \times 100 \%=81.3 \%$} \\
\hline
\end{tabular}

Tabel 4. Hasil Pengujian Skenario ke-2

\begin{tabular}{|c|c|c|c|c|c|c|}
\hline Kategori & Baju & Celana & Kupu - Kupu & Kursi & Sepeda & Total \\
\hline Total Data Uji Benar & 27 & 27 & 18 & 23 & 29 & 124 \\
\hline $\begin{array}{c}\text { Total Seluruh Data yang } \\
\text { Diuji }\end{array}$ & 30 & 30 & 30 & 30 & 30 & 150 \\
\hline
\end{tabular}

Alwanda, et., al ( Implementasi Metode Convolutional Neural Network Menggunakan Arsitektur LeNet-5 untuk Pengenalan Doodle) 
Vol. 1, No. 1, Oktober 2020, Hal. 45 - 56

$$
\text { Accuracy Keseluruhan }=\frac{\sum \text { Data Uji Benar }}{\sum \text { Total Uji }} 100 \%=\frac{124}{150} \times 100 \%=82.6 \%
$$

Tabel 5. Hasil Pengujian Skenario ke-3

\begin{tabular}{|c|c|c|c|c|c|c|}
\hline Kategori & Baju & Celana & Kupu - Kupu & Kursi & Sepeda & Tota \\
\hline Total Data Uji Benar & 26 & 26 & 22 & 2 & 25 & 101 \\
\hline $\begin{array}{c}\text { Total Seluruh Data yang } \\
\text { Diuji }\end{array}$ & 30 & 30 & 30 & 30 & 30 & 150 \\
\hline jo $\quad x$ & & $\frac{\text { Data Uji }}{\sum \text { Total }}$ & $\frac{3 \text { enar }}{J j i} 100$ & $\frac{101}{150} x$ & $\%=$ & \\
\hline
\end{tabular}

Tabel 6. Hasil Pengujian Skenario ke-4

\begin{tabular}{|c|c|c|c|c|c|c|}
\hline Kategori & Baju & Celana & Kupu - Kupu & Kursi & Sepeda & Total \\
\hline Total Data Uji Benar & 25 & 27 & 20 & 3 & 26 & 101 \\
\hline $\begin{array}{c}\text { Total Seluruh Data yang } \\
\text { Diuji }\end{array}$ & 30 & 30 & 30 & 30 & 30 & 150 \\
\hline \multicolumn{7}{|c|}{$\begin{array}{c}\text { A Data Uji Benar } \\
\text { Accuracy Keseluruhan Uji }\end{array}$ - $100 \%=\frac{101}{150} \times 100 \%=67.3 \%$} \\
\hline
\end{tabular}

\section{KESIMPULAN}

Berdasarkan hasil pengujian pada pengenalan doodle menggunakan metode Convolutional Neural Network (CNN) yang telah dilakukan dan telah diuraikan dalam laporan ini, maka dapat ditarik kesimpulan sebagai berikut.

1. Pada pengujian skenario pertama, kedua dan keempat objek doodle sepeda lebih dikenali dibandingkan keempat objek lainnya dengan nilai accuracy sebesar $93 \%-98 \%$, recall $86 \%$ - 93\% dan precision sebesar $81 \%$ - 93\%, sedangkan pada pengujian skenario ketiga objek doodle baju lebih dikenali dibandingkan keempat objek lainnya dengan nilai accuracy $94 \%$, recall $86 \%$, dan precision $83 \%$. Maka dapat disimpulkan penggunaan metode Convolutional Neural Network (CNN) dengan arsitektur LeNet-5 pada penelitian ini objek doodle sepeda lebih banyak dikenali.

2. Untuk pengenalan doodle menggunakan metode Convolutional Neural Network (CNN), penggunaan max pooling lebih baik daripada menggunakan average pooling pada pooling layer yang terdapat pada arsitektur LeNet-5 dikarenakan dalam pengenalan objek tingkat akurasi keseluruhan yang dihasilkan rata - rata sebesar $81 \%$ pada max pooling dan $67 \%$ pada average pooling, ketika melakukan penggambaran secara baik maupun penggambaran secara garis putus - putus.

\section{SARAN}

Adapun saran - saran yang diberikan untuk dilakukan pada penelitian selanjutnya adalah sebagai berikut.

1. Menggunakan metode Convolutional Neural Network (CNN) dengan arsitektur lain seperti AlexNet, VGGNet, GoogLeNet, ResNet, FractalNet dan arsitektur yang lainnya.

2. Menambahkan Transfer Learning pada arsitektur yang akan digunakan.

Alwanda, et., al (Implementasi Metode Convolutional Neural Network Menggunakan Arsitektur LeNet-5 untuk Pengenalan Doodle) 
3. Menambahkan lebih banyak jumlah citra doodle untuk hasil yang lebih baik.

4. Menggunakan fungsi aktivasi lain seperti sigmoid atau reLu.

\section{DAFTAR PUSTAKA}

[1] Ahmad, A. (2017). Mengenal Artificial Intelligence, Machine Learning, Neural Network, dan Deep Learning. Jurnal Teknologi Indonesia.

[2] Basu, S., Das, N., Sarkar, R., Kundu, M., Nasipuri, M., \& Basu, D. K. (2012). Handwritten Bangla Alphabet Recognition using an MLP Based Classifier. 285-291. Diambil dari http://arxiv.org/abs/1203.0882

[3] Tavoli, R., \& Keyvanpour, M. (2018). A method for handwritten word spotting based on particle swarm optimisation and multi-layer perceptron. IET Software, 12(2), 152-159. https://doi.org/10.1049/iet-sen.2017.0071

[4] Eka Putra, W. S. (2016). Klasifikasi Citra Menggunakan Convolutional Neural Network (CNN) pada Caltech 101. Jurnal Teknik ITS, 5(1). https://doi.org/10.12962/j23373539.v5i1.15696

[5] Alom, M. Z., Taha, T. M., Yakopcic, C., Westberg, S., Sidike, P., Nasrin, M. S., ... Asari, V. K. (2018). The History Began from AlexNet: A Comprehensive Survey on Deep Learning Approaches. Diambil dari http://arxiv.org/abs/1803.01164

[6] Wang, S., Wu, T. H., Shao, T., \& Peng, Z. X. (2019). Integrated model of BP neural network and CNN algorithm for automatic wear debris classification. Wear, 426427(September 2018), 1761-1770. https://doi.org/10.1016/j.wear.2018.12.087

[7] Zhou, T., Ruan, S., \& Canu, S. (2019). A review: Deep learning for medical image segmentation using multi-modality fusion. Array, 100004. https://doi.org/10.1016/j.array.2019.100004

[8] Fitriati, D. (2016). Perbandingan Kinerja CNN LeNet 5 Dan Extreme Learning Machine Pada Pengenalan Citra Tulisan Tangan Angka. Jurnal Teknologi Terpadu, 2(1), 10-16.

[9] Zhao, H., \& Liu, H. (2019). Multiple classifiers fusion and CNN feature extraction for handwritten digits recognition. Granular Computing, $0(0), \quad 0$. https://doi.org/10.1007/s41066-019-00158-6

[10] Septianto, T., Setyati, E., \& Santoso, J. (2018). Model CNN LeNet dalam Rekognisi Angka Tahun pada Prasasti Peninggalan Kerajaan Majapahit. 6(April), 106-109. https://doi.org/10.14710/jtsiskom.6.3.2018.106-109

[11] Mariana, G. (2017). Cara Mudah Menggambar Doodle Menggunakan Pensil. Diambil dari https://books.google.co.id/books?isbn=602103659X

[12] Suyanto. (2018). Machine Learning Tingkat Dasar dan Lanjut. Bandung: Informatika Bandung.

[13] Saha, S. (2018). A Comprehensive Guide to Convolutional Neural Networks. Diambil 5 September 2019, dari https://towardsdatascience.com/a-comprehensive-guide-toconvolutional-neural-networks-the-eli5-way-3bd2b1164a53

[14] Zufar, M. (2016). Convolutional Neural Networks untuk Pengenalan Wajah Secara Real - Time. 5(2), 72-77.

[15] Rampasek, L., \& Goldenberg, A. (2016). TensorFlow: Biology's Gateway to Deep Learning? Cell Systems, 2(1), 12-14. https://doi.org/10.1016/j.cels.2016.01.009

[16] Chollet, F. (2015). Keras: The Python Deep Learning library. Diambil dari https://keras.io

Alwanda, et., al ( Implementasi Metode Convolutional Neural Network Menggunakan Arsitektur LeNet-5 untuk Pengenalan Doodle) 